\title{
Seminiferous Epithelium Cycle and Developmental Stages of Spermatids in the Clethrionomys rufocanus
}

\author{
${ }^{\dagger}$ Jung-Hun Lee \\ Department of Science Education, Kyungnam University, Changwon 631-701, Republic of Korea
}

\begin{abstract}
The seminiferous epithelium cycle and developmental stages of spermatids in Clethrionomys rufocanus were observed under a light microscope. The seminiferous epithelium cycle was divided into 8 stages. Type Ad spermatogonia appeared through all stages. Type Ap, In, and B spermatogonia appeared in stages I, II, III, and IV. In the first meiosis prophase, the leptotene spermatocytes appeared from stage $\mathrm{V}$, the zygotene spermatocytes in stages I, VI, VII, VII, the pachytene spermatocytes from stages II to VI, the diplotene spermatocytes in stage VII. The meiotic figures and interkinesis spermatocytes were observed in stage VII. Developing spermatids were subdivided into 10 steps, based on the morphological characteristics such as the acrosome formation changes in spermatozoa, nucleus, cytoplasm, and spermiation changes. The C. rufocanus spermatocytogenesis and spermiogenesis results displayed similar results with Apodemus agrarius coreae and A. speciosus peninsulae. Considering all the results, the spermatogenesis may be useful information to analyze the differentiation of spermatogenic cells and the breeding season.
\end{abstract}

Key words : Clethrionomys rufocanus, Spermatocytogenesis, Spermiogenesis

\section{INTRODUCTION}

Mammalian spermatogenesis is a complicated and elaborate cytological process by which diploid $(2 \mathrm{n})$ called spermatogonia undergo meiosis and produce haploid (n) spermatids (França et al., 1999; Paula et al., 1999; Calvo et al., 2000; Pinart et al., 2000, 2001).

A study on the process of seminiferous epithelium division is the basis to understand the mechanism, the stages of spermatogenesis (Berndtson, 1977), and the morphological characteristics of developing gametes to classify species (França et al., 1999; Kim \& Lee, 2009).

In mammals, the process of spermatogenesis varies among species and differs between seasonality. It is known to be sensitive to temperature and hormonal fluctuations. It differs between hibernating and non-hibernating mammals. The former allows simultaneous synchronous development showing systematic division at all stages of the same type cells in seminiferous tubules (Lee \& Son, 1993; Lee \& Mōri, 2004). While the latter allows non synchronous development showing different type cells in the seminiferous tubule at different stages. The hormonal and protein control mechanisms produce spermatogonia in certain stages and work when spermatogenic cells remain connected to other cells by bridges of cytoplasm, interacting with Leydig cells, Sertoli cells, and other gametes and a constant supply of functional cells occur (de Rooij \& Grootegoed, 1998; Weinbauer \& Wessels, 1999; Garcia-Gil et al., 2002).

Conversely, research on the seminiferous epithelium cycle in mammals such as opossum, Didelphis azarae

\footnotetext{
Manuscript received 3 May 2013, received in revised form 12 May 2013, accepted 16 May, 2013

${ }^{\dagger}$ Corresponding Author : Jung-Hun Lee, Department of Science Education, Kyungnam University, 449 Woryeong-dong Masanhappo-gu, Changwon-si, Gyeongsangnam-do, 631-701, Republic of Korea. Tel. : +82-55-249-2243, Fax : +82-55-249-2014, E-mail : jhlee@kyungnam.ac.kr

This is an Open Access article distributed under the terms of the Creative Commons Attribution Non-Commercial License(http:// creativecommons. org/licenses/by-nc/3.0) which permits unrestricted non-commercial use, distribution, and reproduction in any medium, provided the original work is properly cited.
} 
(Orisi \& Ferreira, 1978; Worawittayawong et al., 2005), Watase's shrew, Crocidura watasei (Adachi et al., 1992), Djungarian hamster, Phodophus sungorus sungorus (van Haaster \& de Rooij, 1993), Musk shrew, Suncus murinus (Kurohmaru et al., 1994), Japanese shrew mole, Urotrichus talpoides (Mizukami et al., 2001), Mongilian gerbil, Meriones unguiculatus (Segatelli et al., 2002), Korean squirrel, Tamias sibiricus (Jung \& Lee, 2004), Crocidura shantungensis (Jeong \& Lee, 2005), Crocidura dsinezumi (Jeong \& Lee, 2006), Apodemus agrarius coreae (Lee, 2007), Apodemus speciosus peninsulae (Kim \& Lee, 2009) were previously widely done, but Clethrionomys rufocanus research has not been reported yet. Thus, this study examines the stages of Clethrionomys rufocanus spermatogenesis and investigates its difference with other rodents.

\section{MATERIALS AND METHODS}

5 male Clethrionomys rufocanus, for this study, were caught in a Sherman trap from Mount Jiri (altitude of 1,000 to $1,100 \mathrm{~m}$ ) in Gyeongnam, Korea, were transported to the laboratory, and anesthetized with chloroform to extract a testicular tissue from each. The testicular tissues were placed in $3 \%$ of glutaraldehyde solution $\left(4^{\circ} \mathrm{C}, \mathrm{pH}\right.$ 7.4, Millong's buffer) for two hours to get the tunicae albugineae incised. The testicular tissues were then rinsed for 10 minutes thrice in $\mathrm{pH} 7.4$, Millong's buffer and 1 to $1.5 \mathrm{~mm}^{3}$ incision was made. They were fixed in the same solution (3\% glutaraldehyde) again for three hours. Fixed tissues were rinsed in solution ( $\mathrm{pH} 7.4$, Millong's buffer) for 10 minutes thrice and were fixed again in $1.33 \%$ $\mathrm{OsO}_{4}$ ( $\mathrm{pH} 7.4$, Millong's buffer). The re-fixed tissues were rinsed in the same solution for 10 minutes thrice and dewatered in acetone (60-100\%). Afterwards the tissue samples were placed in Epon 812 and sections were cut at $400 \mathrm{~nm}$ thick on a ultra microtome (MT-6000, Sorvall, Dupont). The resulting tissue sections were stained with $0.5 \%$ of toluidine and were analyzed by microscopy.

\section{RESULTS}

The Clethrionomys rufocanus' seminiferous epithelium cycle during spermatocytogenesis and spermiogenesis is divided into 8 stages (Figs. 1(a-h), 2). The spermiogenesis process is divided into 10 steps based on the morphological change in the nucleus and cytoplasm, the formation of head and tail, in spermatids; the Golgi phase (steps 1 and 2), the cap phase (steps 3 and 4), the acrosomal phase (steps 5 and 6), the maturation phase (steps 7 and 8), and the spermiation phase (steps 9 and 10). Each phase was differentiated between early and late step. Type Ad spermatogonium was observed in each seminiferous epithelium cycle stage.

\section{Stage I}

At this stage, type Ap spermatogonia with pale nuclei and type Ad spermatogonia with dark nucleus are attached to the basal laminae. Also, primary zygotene spermatocytes from meiosis 1 , spermatids in the early Golgi phase $\left(\mathrm{St}_{1}\right.$, step 1) and spermatozoon in early spermiation ( $\mathrm{St}_{9}$, step 9) released from Sertoli cells, were widely observed (Fig. 1a).

\section{Stage II}

The upper compartment of the basal lumina has type Ad spermatogonia and intermediate cells that are smaller than type Ad spermatogonia. Pachytene spermatocytes were observed for the first time. Late Golgi spermatids $\left(\mathrm{St}_{2}\right.$, step 2), spermatids being released from Sertoli cells in late spermiation phase $\left(\mathrm{St}_{10}\right.$, step 10$)$, and other sperm cells were observed as well (Fig. 1b).

\section{Stage III}

Like in stages $\mathrm{I}$ and II, type Ad spermatogonia and type B spermatogonia, which reside in the basal compartment, were observed for the first time. Many spermatids in early cap phase $\left(\mathrm{St}_{3}\right.$, step 3$)$ including spermatocytes in pachytene were observed as well (Fig. 1c).

\section{Stage IV}

Like in stage III, type Ad spermatogonia and type B spermatogonia were observed. From the upper section of 
those cells, pachytene spermatocytes and many spermatids in late cap phase $\left(\mathrm{St}_{4}\right.$, step 4) were found (Fig. 1d).

\section{Stage V}

Like the previous stages, type Ad spermatogonia were observed. Leptotene spermatocytes and pachytene spermatocytes were observed for the first time at this stage. The nuclei are increased at the rear, becoming the acrosome and spermatids in early acrosomal phase ( $\mathrm{St}_{5}$, step 5$)$ were observed (Fig. 1e).
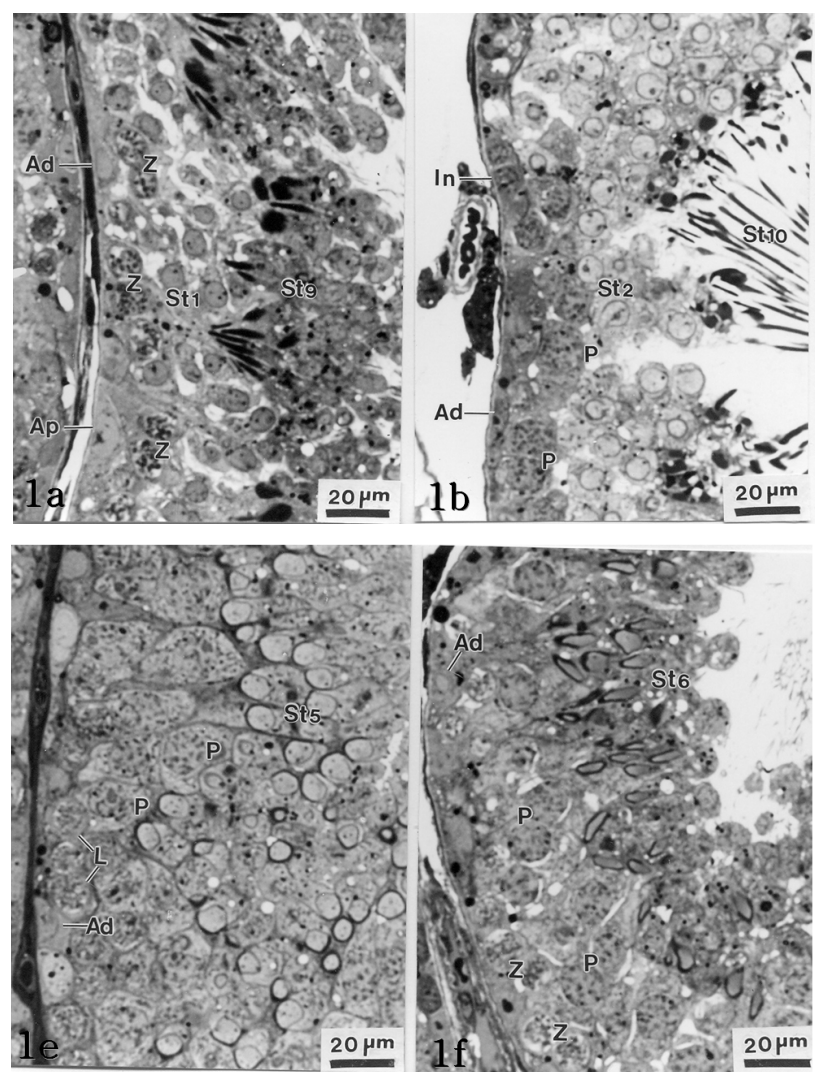
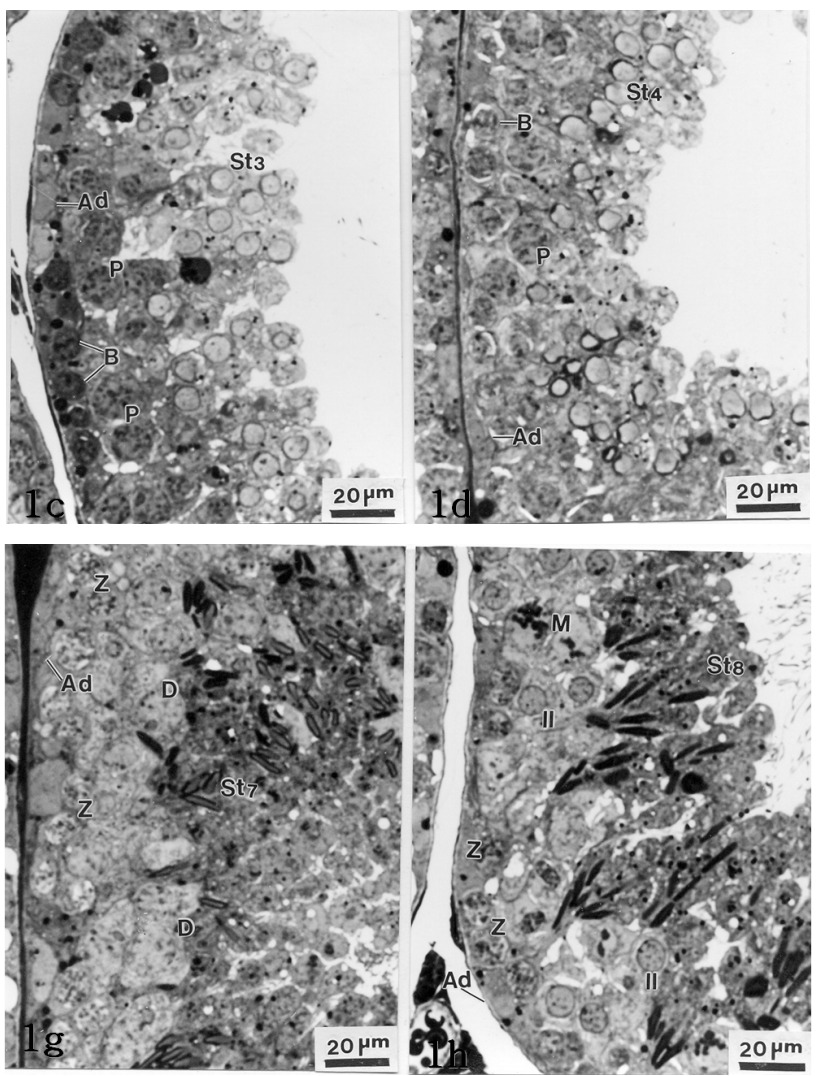

Fig. 1. Stages 1-8 of the seminiferous epithelium cycle in the Clethrionomys rufocanus. Stage 1 (1a) shows dark (Ad) and pale (Ap) types of spermatogonia, zygotene (Z) primary spermatocytes, early Golgi phase of spermatids $\left(\mathrm{St}_{1}\right)$ and early spermiation phase of spermatids ( $\left.\mathrm{St}_{9}\right)$. Stage $2(1 \mathrm{~b})$ presents dark and intermediate (In) spermatogonia, pachytene (P) spermatocytes, late Golgi spermatids $\left(\mathrm{St}_{2}\right)$ and late spermiation phase of spermatids $\left(\mathrm{St}_{10}\right)$. Stage 3 (1c) contains types of dark and $\mathrm{B}$ types of spermatogonia, pachytene spermatocytes and early cap phase of spermatids $\left(\mathrm{St}_{3}\right)$. Stage 4 (1d) shows dark and B types of spermatogonia, and late cap phase of spermatids $\left(\mathrm{St}_{4}\right)$. Stage 5 (1e) contains dark type of spermatogonia, leptotene (L) and pachytene spermatocytes, and early acrosomal phase of spermatids ( $\left.\mathrm{St}_{5}\right)$. Stage 6 (1f) presents dark type of spermatogonia, zygotene $(\mathrm{Z})$, pachytene spermatocytes and late acrosomal phase of spermatids $\left(\mathrm{St}_{6}\right)$. Stage 7 (1g) shows dark type of spermatogonia, zygotene, diplotene (D) spermatocytes and early maturation phase of spermatids $\left(\mathrm{St}_{7}\right)$. Stage $8(\mathrm{~h})$ shows dark type of spermatogonia, zygotene spermatocytes, metaphase $(\mathrm{M})$ and interkinesis (II) of first meiotic division, and late maturation phase of spermatids $\left(\mathrm{St}_{8}\right)$. 
In the same way of stage VI, type Ad spermatogonia and zygotene spermatocytes were found close to the basal compartment. Diplotene spermatocytes and spermatids in early maturation phase ( $\mathrm{St}_{7}$. step 7 ) were observed (Fig. 1g). Spermatids, at this stage, had slightly elongated nuclei and were more condensed than the ones in stage VI. Spermatids cytoplasms decreased in volume compared to stage VI (Fig. 1g).

\section{Stage VIII}

Type Ad spermatogonia and zygotene spermatocytes were found closely to the basal compartment. Undergoing first meiotic division, nucleoplasm was equalized and interkinesis spermatocytes were shown. The spermatids, in the late maturation phase $\left(\mathrm{St}_{8}\right.$, step 8$)$, were found showing further elongated cells with condensed and more equalized nuclei (Fig. 1h).

\section{DISCUSSION}

This study was based on mitosis, meiosis, and three continuous processes after meiosis. From observing the acrosome formation change in the spermatids, nucleus, and cytoplasm during the spermiation (Kurohmaru et al., 1988; Adachi et al., 1992; van Haaster \& de Rooil, 1993), where spermatozoa are released from the Sertoli cells, the findings are as follows: seminiferous epithelium cycle of Clethrionomys rufocanus has 8 stages and spermatogenesis had 10 phases (Figs. 1, 2). The Clethrionomys rufocanus's seminiferous epithelium cycle is divided into 8 stages and the spermatids process is divided into 10 steps based on the morphological change in spermatids; the Golgi phase (steps 1 and 2), the cap phase (steps 3 and 4), the acrosomal phase (steps 5 and 6), the maturation phase (steps 7 and 8), and the spermiation phase (steps 9 and 10). Each phase was differentiated between early and late steps, dividing spermiogenesis into 10 phases (Figs. 1, 2).

Comparing the seminiferous epithelium cycle in Clethrionomys rufocanus with other rodents, the Clethrionomys rufocanus had the shortest cycle, with only eight stages (Figs. 1, 2 and
Table 1). The Crocidura shantungensis (Jeong \& Lee, 2005) had 14 stages and Suncus murinus (Kurohmaru et al., 1994) had 13 stages. Crocidura watasei (Adachi et al., 1992), Phodopus sungorus sungorus (van Haaster \& de Rooij, 1993), Urotrichus talpoides (Mizukami et al., 2001), Meriones unguiculatus (Segatelli et al., 2002), Tamias sibiricus (Jung \& Lee, 2004) and Crocidura dsinezumi (Jeong \& Lee, 2006) had 12 stages. Didelphis azarae (Orisi $\&$ Ferreira, 1978) and Apodemus agrarius coreae (Lee, 2007) had 10 stages. Bandicota indica (Worawittayawong et al., 2005) and Apodemus speciosus peninsulae (Kim \& Lee, 2009) had 9 stages (Table 1).

The Crocidurinae had longer cycles than the muroids, but the Clethrionomys rufocanus exhibited the shortest cycle (Table 1). The difference in spermatogenesis is related to the breeding season (Jeong \& Lee, 2005) the same family level has almost similar cycle to complete spermiation, which is inferred from specific characteristics in species (Adachi et al., 1992; Kurohmaru et al., 1994). Therefore, the seminiferous epithelium cycle can give useful information to acknowledge maturation in spermatids and breeding season. Particularly, Apodemus agrarius coreae shows 10 stages (Lee, 2007) and A. speciosus peninsulae shows 11 stages (Kim \& Lee, 2009) and Clethrionomys rufocanus showed 8 stages, which for survival strategy means they want to preserve its kinds and regulate breeding.

From the previous research and this research, type Ad spermatogonia appeared in all stages, in all species (Table $2)$, which proves all rodents show common spermatogonia as Lee (2007) stated. Clethrionomys rufocanus, type Ap spermatogonia appeared in stage I (Fig. 2), and it confirms seminiferous epithelium cycle has the shortest cycle as Table 2 shows.

Comparing type In spermatogonia appearance, the Japanese shrew mole, Urotrichus talpoides (Mizukami et al., 2001) had it in stage I and Clethrionomys rufocanus showed it in stage $I$, which is faster than other rodents (Table 2).

As Table 2 shows, most of the species showed type B spermatogonia throughout stages II to VI but contrastingly 


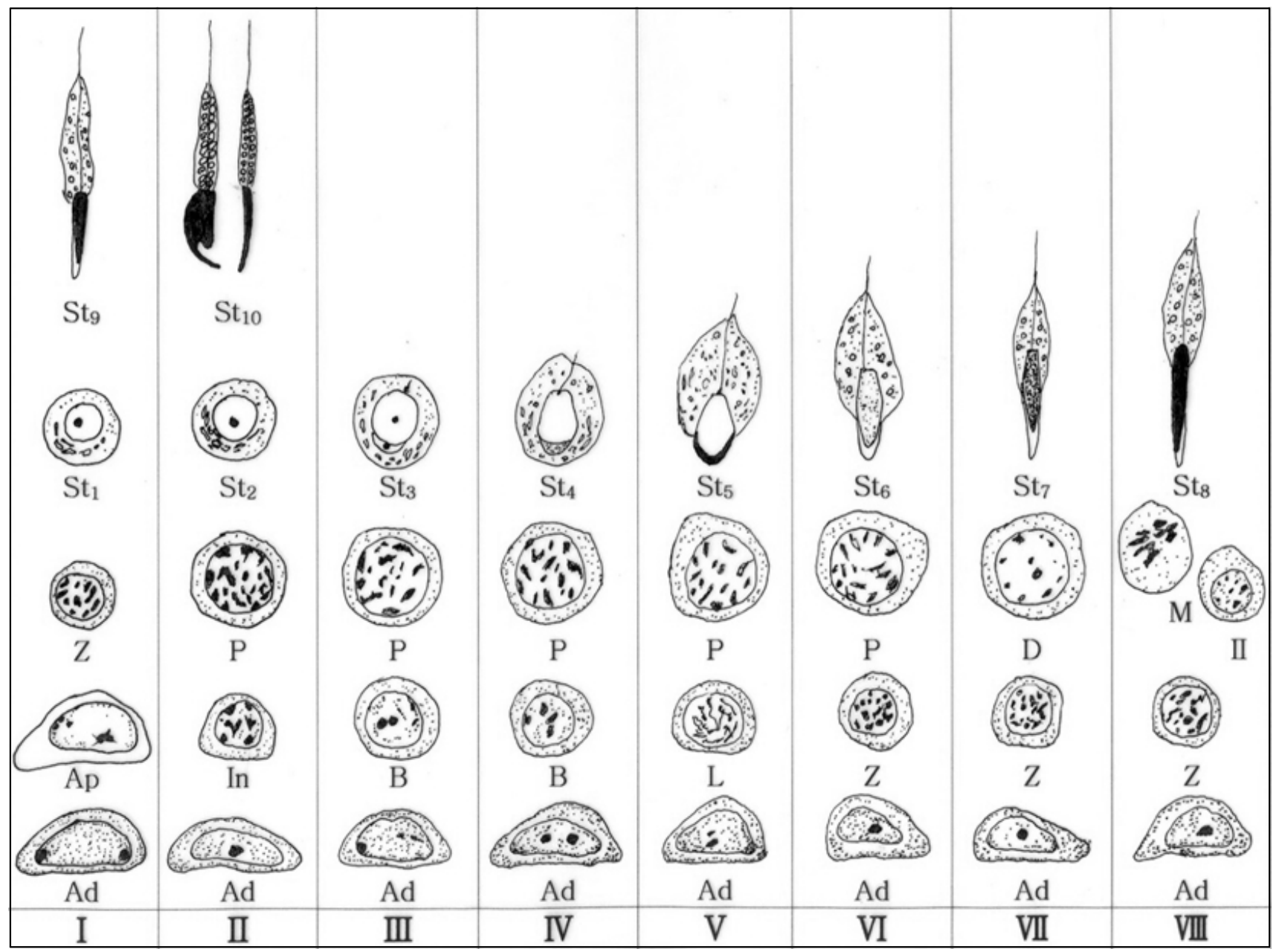

Fig. 2. Schematic drawing of the cycle of the seminiferous epithelium in Clethrionomys rufocanus. Roman numerals represent each stage. Arabic numerals beneath each spermatid show each step during spermiogenesis. All stages of $\mathrm{St}_{1}$ to $\mathrm{St}_{10}$ spermatids were consisted of early and late phases, respectively.

Ad, dark type of spermatogonia; Ap, pale type of spermatogonia; B, B type of spermatogonia; D, diplotene spermatocytes; In, intermediate type of spermatogonia; L, leptotene spermatocytes; M, mtaphase of first meiotic division; P, pachytene spermatocytes; Z, zygotene spermatocytes; II, interkinesis of first meiotic division.

the experimental species, Clethrionomys rufocanus, had it in stages III and IV. By analyzing at what stage type In spermatogonia and B spermatogonia appear, considering that Bandicota indica and Suncus murinus that inhabit warmer region had faster cell division than other species, we can see that inhabiting environment affects spermiation as the previous studies stated that continuity of stages and stem cells are influenced by temperature (van Haaster \& de Rooij, 1993; Levy et al.,1999; Toyama et al., 1999; Pinart et al., 2000).

During spermatocytogenesis, pre-leptotene spermatocyte appear throughout stages VI to VIII in most species, but it was not observed in the experimental species. However the experimental species, Clethrionomys rufocanus, showed leptotene spermatocyte in stage $V$ for the first time whereas leptotene spermatocyte are normally shown throughout stages $V$ to $X I$. This is shown in Tables 2 and 3 that type Ad spermatogonia, type Ap spermatogonia, type B spermatogonia appear faster than in other species during spermatocytogenesis (Table 2, 3). Contrastingly, comparing to the Crocidurinae and Sciurus, Clethrionomys rufocanus had a little slower division which is distinctive. 
Table 1. Comparison of the seminiferous epithelium cycle in mammals

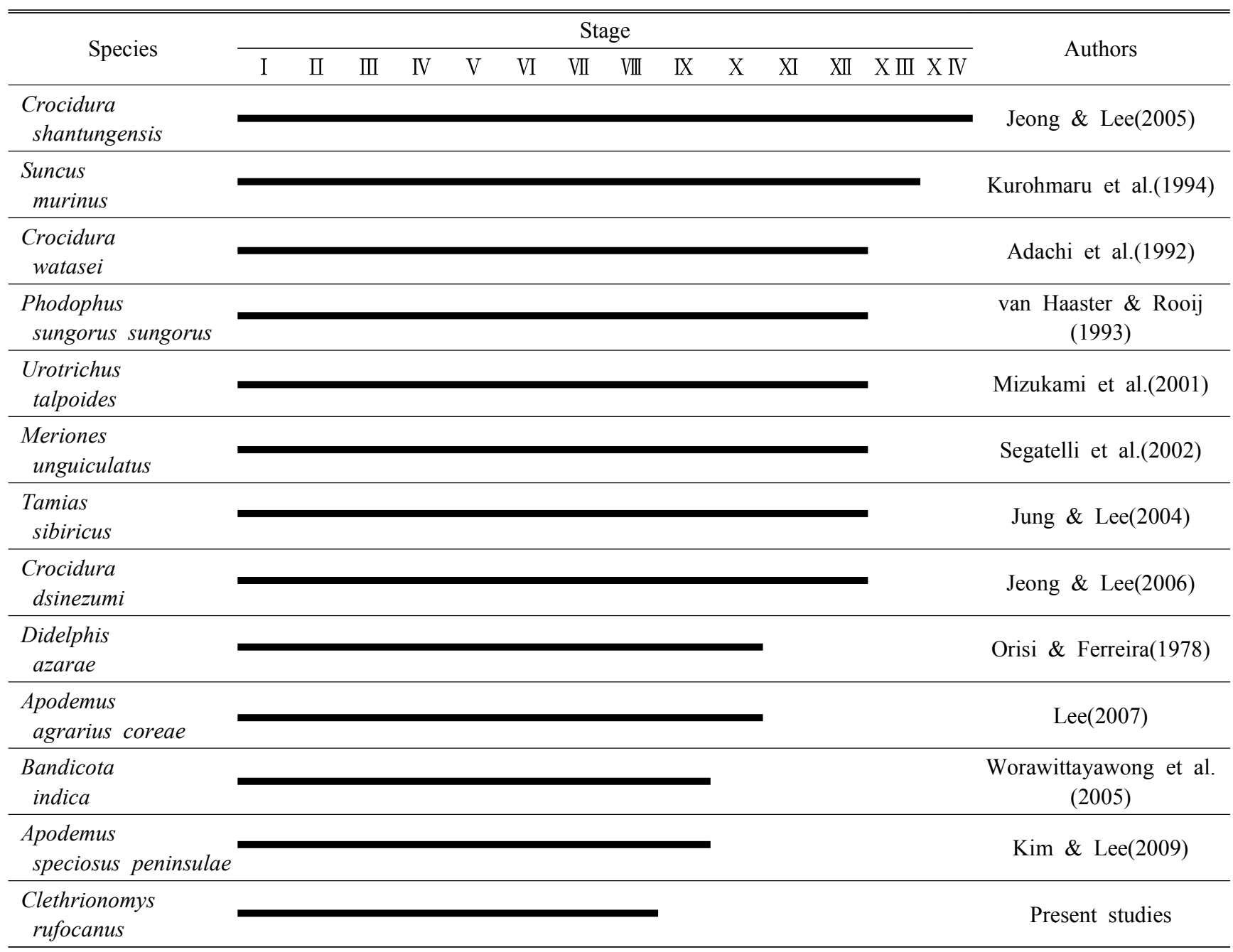

For each species, zygotene spermatocyte appears at a different time throughout stages I to X IV, but Clethrionomys rufocanus had zygotene spermatocyte in stages I, VI, VII, VIII (Table 3). In addition, pachytene spermatocyte were widely observed throughout all stages; from I to XII for Bandicota indica, Phodopus sungorus, Urotrichus talpoides, Tamias sibiricus, Crocidura watasei, Suncus murinus, Crocidura shantungensis, but in Clethrionomys rufocanus it occurred in stage II, Apodemus agrarius coreae and $A$. speciosus peninsulae had them in stages III, VII, VII respectively. It means that zygotene spermatocyte appear slightly later. This result shows that Apodemus agrarius coreae, A. speciosus peninsulae, and Clethrionomys rufocanus have species-specific characteristics (Table 3 ).
At stage VII, diplotene spermatocyte was observed, which is the fastest than in other species. Stage 8 shows metaphase and interkinesis spermatocyte in the first meiotic division, which is also the fastest (Table 3). Considering at what stages spermatogonia and spermatocytes appear, Clethrionomys rufocanus had similar results with Apodemus agrarius coreae, A. speciosus peninsulae. This indicates they are closely related.

As Table 4 shows, Opossum, Didelphis azarae (Orisi \& Ferreira, 1978), Crocidura shantungensis (Jeong \& Lee, 2005), Meriones unguiculatus (Segatelli et al., 2002) had 15 phases for spermiogenesis, whereas Crocidura dsinezumi (Jeong \& Lee, 2006) had 14 phases. Watase's shrew, Crocidura watasei (Adachi et al., 1992) and the musk 
Table 2. Comparison of cell types and stages of appearance of spermatogonia in the seminiferous tubules of mammals

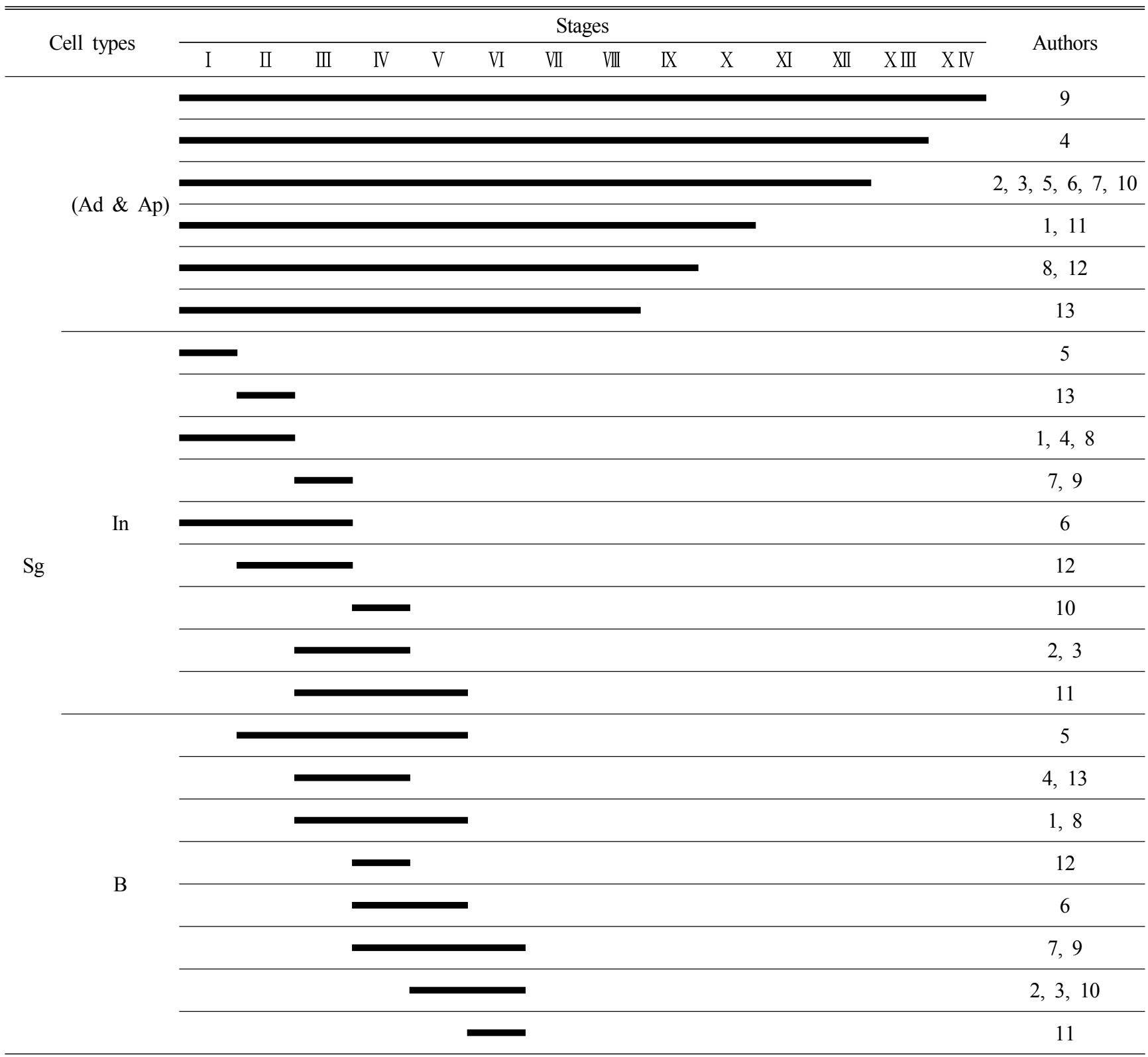

Ad, dark type of spermatogonia; Ap, pale typte of spermatogonia; B, B type of spermatogonia; In, intermediate type of spermatogonia; Sg, spermatogonia; 1, Didelphis azarae (Orisi \& Ferreira, 1978); 2, Crocidura watasei (Adachi et al., 1992); 3, Phodophus sungorus sungorus (van Haaster \& Rooij, 1993); 4, Suncus murinus (Kurohmaru et al., 1994); 5, Urotrichus talpoides (Mizukami et al., 2001); 6, Meriones unguiculatus (Segatelli et al., 2002); 7, Tamias sibiricus (Jung \& Lee, 2004); 8, Bandicota indica (Worawittayawong et al., 2005); 9, Crocidura shantungensis (Jeong \& Lee, 2005); 10, Crocidura dsinezumi (Jeong \& Lee, 2006); 11, Apodemus agrarius coreae (Lee, 2007); 12, Apodemus speciosus peninsulae (Kim \& Lee, 2009); 13, Clethrionomys rufocanus.

shrew, Suncus murinus (Kurohmaru et al., 1994) had 13 phases. Djungarian hamster, Phodophus sungorus (van Haaster \& Rooij, 1993) and the Japanese shrew mole, Urotrichus talpoides (Mizukami et al., 2001), the Korean squirrel, Tamias sibiricus (Jung \& Lee, 2004), and the
Apodemus speciosus peninsulae (Kim \& Lee, 2009) had 12 phases. Except for the bandicoot rat, Bandicota indica (Worawittayawong et al., 2005), Apodemus agrarius coreae (Lee, 2007) and Clethrionomys rufocanus has the shortest number of phases with 10 (Table 4). 
Table 3. Comparison of cell types and stage of appearance of primary spermatocytes in the seminiferous tubules of mammals

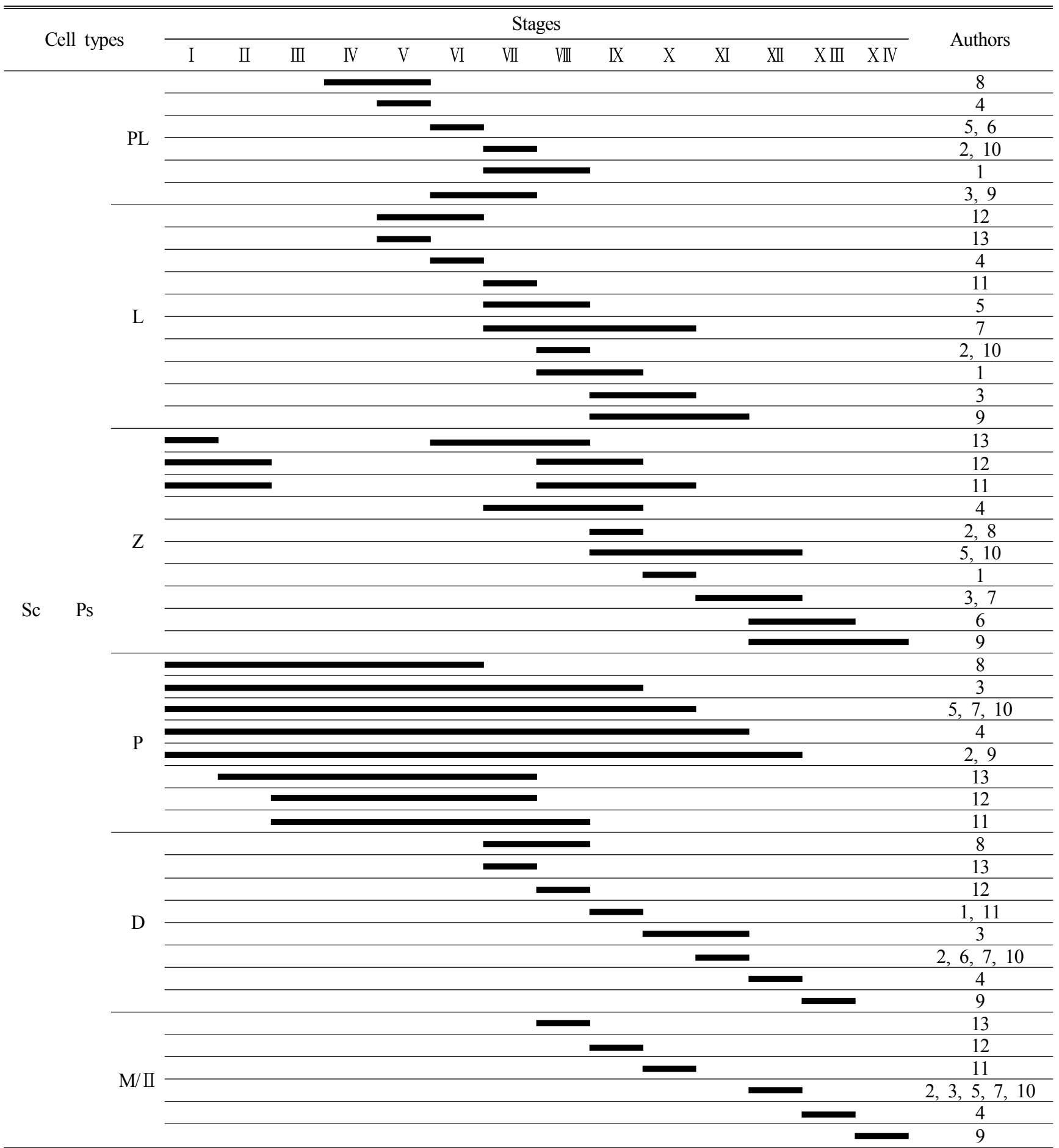

$\mathrm{D}$, diplotene spermatocyte; L, leptotene spermatocyte; M, metaphase of first meiotic division; II, interkinesis; P, pachytene spermatocyte; PL, pre-leptotene spermatocyte; Ps, primary spermatocytes; Sc, spermatocytes; Z, zygote spermatocyte; 1, Didelphis azarae (Orisi \& Ferreira, 1978); 2, Crocidura watasei (Adachi et al., 1992); 3, Phodophus sungorus sungorus (van Haaster \& Rooij, 1993); 4, Suncus murinus (Kurohmaru et al., 1994); 5, Urotrichus talpoides (Mizukami et al., 2001); 6, Meriones unguiculatus (Segatelli et al., 2002); 7, Tamias sibiricus (Jung \& Lee, 2004); 8, Bandicota indica (Worawittayawong et al., 2005); 9, Crocidura shantungensis (Jeong \& Lee, 2005); 10, Crocidura dsinezumi (Jeong \& Lee, 2006); 11, Apodemus agrarius coreae (Lee, 2007); 12, Apodemus speciosus peninsulae (Kim \& Lee, 2009); 13, Clethrionomys rufocanus (Present studies). 
Table 4. Comparison of developmental stages of spermatids in the seminiferous tubules of mammals

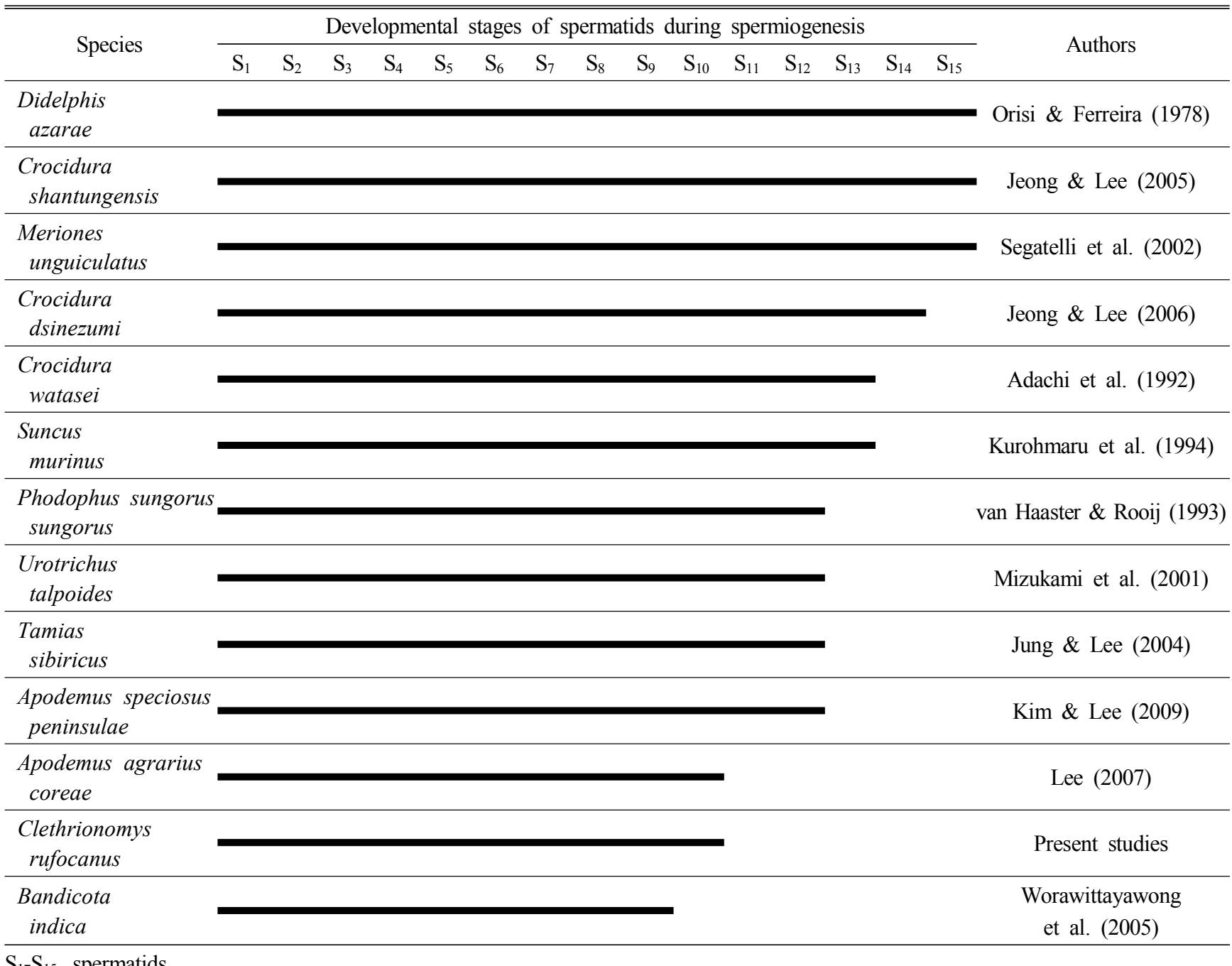

These results show that Clethrionomys rufocanus completes spermatogenesis faster than other rodents, which will affect their breeding since they are more active in producing spermatids. Although most mammals have a regulated typical structure for spermatogenesis, but between species they show different morphological characteristics and different number of spermatozoa to produce (Okwun et al., 1996; França et al., 1999). Various mammals have their own species specificity in seminiferous epithelium cycle, number of stages to undergo for spermiogenesis, and timeline for the same type of spermatogonia to form (Adachi et al., 1992; Kurohmaru et al., 1994). Considering all the results, the spermatogenesis may be useful infor- mation to analyze the differentiation of spermatogenic cells and the breeding season.

\section{ACKNOWLEDGMENT}

This work was supported by Kyungnam University Research Found 2011.

\section{REFERENCES}

Adachi Y, Kurohmaru M, Hattori S, Hayashi Y (1992) Spermatogenesis in the Watase's shrew, Crocidura watasei: A light and electron microscopic study. Exp 
Anim 41:295-303.

Berndtson WE (1977) Methods for quantifying mammalian spermatogenesis: a review. J Anim Sci 44:818-833.

Calvo A, Pastor LM, Bonet S, Pinart E, Ventura M (2000) Characterization of the glycoconjugates of boar testis and epididymis. J Reprod Fertil 120:325-335.

de Rooij DG, Grootegoed JA (1998) Spermatogonial stem cells. Cell Biol 10:694-701.

França LR, Becker-Silva SC, Chiarini-Garcia H (1999) The length of the cycle of seminiferous epithelium in goat (Capra hircus). Tissue \& Cell 31:74-80.

Garcia-Gil N, Pinart E, Sancho S, Badia E, Bassols J, Kádár E, Briz M, Bonet S (2002) The cycle of the seminiferous epithelium in landrace boars. Anim Reprod Sci 73:211-225.

Jeong SD, Lee JH (2005) Seminiferous epithelium cycle of Crocidura shantungensis. Dev Reprod 10:9-17. (Korean)

Jeong SD, Lee JH (2006) Seminiferous epithelium cycle of Crocidura dsinezumi. J Exp Biomed Sci 11:545553.(Korean)

Jung TD, Lee JH (2004) Seminiferous epithelium cycle in the Korean squirrel, Tamias sibiricus. J Exp Biomed Sci 10:275-283. (Korean)

Kim MJ, Lee JH (2009) Seminiferous epithelium cycle of Apodemus speciosus peninsulae. Dev Reprod 13:25-33. (Korean)

Kurohmaru M, Kobayashi H, Hattori S, Nishida T, Hayashi Y (1994) Spermatogenesis and ultrastructure of a peculiar acrosomal formation in the musk shrew, Suncus murinus. J Anat 185:503-509.

Kurohmaru M, Tiba T, Nishida N, Hayashi Y (1988) Spermatogenesis and ultrastuctural changes of spermatids during spermiogenesis in the cotton rat, Sigmodon hispidus. Okajimas Folia Ana Jpn 65:203-219.

Lee JH (2007) Seminiferous epithelium cycle and developmental stages of spermatids in the Apodemus agrarius coreae. J Exp Biomed Sci 13:61-69. (Korean)

Lee JH, Mōri T (2004) Annual cycle of the seminiferous epithelium of Myotis macrodactylus. J Fac Agr Kyushu
Univ 49:355-365.

Lee JH, Son SW (1993) Periodic changes of the male reproductive organs and electrophoretic pattern of proteins in the Korean greater horseshoe bat, Rhinolophus ferrumequinum Korai. Korean J Electr Micros 23: 30-60. (Korean)

Levy S, Serre V, Hermo L, Robaire B (1999) The effects of aging on the seminiferous epithelium and the blood testis barrier of the Brown Norway rat. J Androl 20: 356-365.

Mizukami T, Kuwahara S, Ohmura M, Iinuma Y, Izumikubo J, Hagiwara M, Kurohmaru M, Hayashi Y, Nishida T (2001) The cycle of the seminiferous epithelium in the greater Japanese shrew mole, Urotrichus talpoides. J Vet Med Sci 63:31-35.

Okwun OE, Igboeli G, Ford JJ, Lunstra DD, Johnson L (1996) Number and function of Sertoli cells, number and yield of spermatogonia, and daily sperm production in three breeds of boars. J Reprod Fertil 107:137-149.

Orisi AM, Ferreira AL (1978) Definition of the stages of the cycle of the seminiferous epithelium of the opossum (Didelphis azarae). Acta Anat 100:153-160.

Paula TA, Chiarini-Garcia H, França LR (1999) Seminiferous epithelium cycle and its duration in capybaras (Hydrochoerus hydrochaeris). Tissue \& Cell 31:327-334.

Pinart E, Sancho S, Briz MD, Bonet S, Garcia N, Badia E (2000) Ultrastructural study of the boar seminiferous epithelium: Changes in cryptorchidism. J Morphol 244: 190-202.

Pinart E, Bonet S, Briz MD, Pastor LM, Sancho S, Garcia N, Badia E, Bassols J (2001) Lectin affinity of the seminiferous epithelium in health and eryptorchid post-puberal boars. J Andro 24:153-164.

Segatelli TM, Almeida CCD, Pinheiro PFF, Martinez M, Padovani CR, Martinez. FE (2002) Kinetics of spermatogenesis in the Mongolian gerbil (Meriones unguiculatus). Tissue \& Cell 34:7-13.

Toyama Y, Maekawa M, Kadomatsu K, Miyauchi T, Muramatsu T, Yuasa S (1999) Histological characterization of defective spermatogenesis in mice lacking the basigin 
gene. Anat Histol Embryol 28:205-213.

van Haaster LH, de Rooij DG (1993) Cycle of the seminiferous epithelium in the Djungarian hamster (Phodopus sungorus sungorus). Biol Reprod. 48:515-521.

Weinbauer GF, Wessels J (1999) 'Paracrine' control of spermatogenesis. Andrologia 31:242-262.
Worawittayawong P, Leigh CM, Cozens G, Peirce EJ, Setchell BP, Sretarugsa P, Dharmarajan A, Breed WG (2005) Unusal germ cell organization in the seminiferous epithelium of a murid rodent from southern Asia, the greater bandicoot rat, Bandicota indica. Int J Androl 38:180-188. 